\title{
EL CAPITAL SOCIAL EN LAS DIVERSAS FORMAS DE LA SOCIEDAD ANÓNIMA, LOS PRINCIPIOS Y LAS DIVERSAS FUNCIONES QUE CUMPLE TANTO EXTERNA COMO INTERNAMENTE EN ESTAS
}

\author{
VicENTE RodOLFo WALDE JÁUREGUI*
}

\begin{abstract}
Resumen
Dentro del sistema mercantil la Sociedad Anónima ocupa un lugar relevante, como se evidencia al realizar un análisis histórico de esta forma societaria; siendo merecedora de una especial regulación legal como contrato tipo de sociedad; alcanzando actualmente gran diversificación, influencia y desarrollo bajo diversas formas societarias. La Sociedad Anónima deviene así en una figura jurídica que reposa sobre el concepto de "capital" que constituye su esencia, término cuya comprensión parte de la distinción entre "patrimonio" y "capital social"; capital social que se encuentra regulado por el principio de Determinación y Unidad del Capital Social, y el principio de Estabilidad del Capital, los mismos que completan la defensa del capital de la sociedad por acciones, con los cuales se le pretende dar una protección adecuada a los negocios.
\end{abstract}

Palabras clave: Sociedad Anónima - Derecho Societario - Sociedades Anónimas Cerradas - Sociedades Anónimas Abiertas - Patrimonio Social Capital Social - Aumento y de reducción del capital social.

\begin{abstract}
Inside the mercantile system, the joint-stock company is relevant, evidenced by a historical analysis of this corporate form. This is worthy of a special legal regulation as contract type of company; currently reaching great diversification, influence and development under various corporate forms. The joint stock company thus becomes a legal figure that rests on the concept of "capital" which is his essence, term whose understanding is based on the distinction between "patrimony" and "social capital"; social capital that is governed by the principles of determination and unity of the Social Capital, and stability of Capital, those who complete the defence of the capital of the company by shares, with which to try give adequate protection to the business.
\end{abstract}

Key words: Joint stock company - Corporate Law - Closed joint stock company - Open joint stock company - Social Patrimony - Social capital Increase and reduction of the social capital.

\section{Sumario}

1. Antecedentes Históricos. 2. Sistemas legislativos de la época. 3. Sistemas legislativos de la época: a) Sistema del "octroi"; b) Sistema de la Autorización Gubernativa; c) Sistema de las Disposiciones Normativas. 4. El capital

* Juez de la Corte Suprema de Justicia de la República. 
Vicente Rodolfo Walde Jáuregui - El capital social en las diversas formas de la sociedad anónima, los principios y las diversas funciones que cumple tanto externa como internamente en estas

social, alternativas y principios. 5. Aumento y reducción del capital social. 6. Motivaciones jurídicas e históricas de la sociedad anónima en el derecho comparado y sus relaciones con la legislación interna. 7. Sociedad Anónima ente eminentemente de capitales. 8. El capital de la sociedad. 9. Desarrollo de las autorizaciones y plazos del aumento del capital en el Derecho Comparado. 10. El Acuerdo de Reducción de la cifra del capital. 11. La garantía de los acreedores. 12. Protección de los acreedores. 13. Derecho de Oposición. 14. Derecho a la garantía de los créditos. 15. La agrupación y amortización de títulos accionarios en el sistema español. 16. Amortización de acciones que no afecte a todas por igual. 17. Derecho Comparado. 18. La reducción del capital en el Derecho Comparado.

Los temas que pretendemos analizar en la buena doctrina del Derecho Societario, resultan ser relevantes, porque interactúan con elementos básicos en el ámbito corporativo societario; en nuestro país el análisis tiene que centrarse en reconocer que a partir de la Ley 26887, Ley General de Sociedades (01-01-98), no nos hemos quedado en el tratamiento de una Sociedad Anónima que solo reconocía su forma ordinaria que debía pasar por diversas formas de constitución, sino que tenemos que agregar en este análisis las virtualidades jurídicas que impregnan a las formas societarias especiales establecidas en la ley de la materia, como son las Sociedades Anónimas Cerradas (S.A.C.) y las Sociedades Anónimas Abiertas (S.A.A.), reconociendo desde ahora que algunos derechos fundamentales en la sociedad mercantil ya no tienen el rigor formal ineludible de una regla básica como por ejemplo el derecho fundamental de votar o el derecho fundamental de preferencia en la emisión de nuevas acciones, porque la Ley vigente estatuye que puedan emitirse acciones sin derecho a voto o mantenerse acciones en cartera, $\mathrm{y}$, en cuanto a la preferencia, los pactos que se celebren para mantenerlas vigentes en una de las nuevas formas societarias, como ocurre por ejemplo con la Sociedad Anónima Abierta, se consideran que están impregnados de una nulidad insalvable.

\section{ANTECEDENTES HISTÓRICOS}

Es menester que como un primer punto de partida hagamos un análisis histórico de esta forma societaria de tanta relevancia en nuestro sistema mercantil, al cual la Ley vigente le ha otorgado una especial regulación para convertirla en el contrato tipo de sociedad, que es eminentemente de capitales. Siguiendo las citas históricas que nos refiere el tratadista español Joaquín Garrigues en su Libro "Curso de Derecho Mercantil" se puede hacer la siguiente referencia ${ }^{1}$ :

Sobre los antecedentes italianos y holandeses, algunos juristas han creído que la S.A. nació como un desenvolvimiento de la s. com.: de la idea de

1 Garrigues, Joaquín. Curso de Derecho Mercantil. Tomo I 7ma. Edición. Madrid: Editorial «Aguirre», 1976, p. 408. 
Vicente Rodolfo Walde Jáuregui - El capital social en las diversas formas de la sociedad anónima, los principios y las diversas funciones que cumple tanto externa como internamente en estas

una sociedad en la cual varios asociados tenían tan solo una responsabilidad limitada para pasar fácilmente a la de una sociedad en la que nadie quedaría comprometido más que por el capital social. Sin embargo, hay opinión mayoritaria, con fundada razón, que estima que la S.A. y la comanditaria han nacido y se han desenvuelto por cauces distintos. En el origen de la sociedad anónima se descubren dos vertientes históricas diversas: la italiana, donde vemos surgir el germen de esta sociedad en las relaciones entre el Estado y sus acreedores, y la holandesa, que aparece ligada al comercio con las Indias orientales y occidentales de principios del siglo XVII, con las cuales se logró un gran desplazamiento patrimonial en esa época.

Las antiguas formas societarias conocidas en el Derecho Romano (societatis vectigalium publicorum) solo tienen elementos comunes con la moderna S.A. en el carácter corporativo y la forma como se transmiten los derechos sociales que le corresponden a la sociedad, sin embargo encontramos una semejanza más notoria con la S.A. moderna en las asociaciones de acreedores del Estado, que se presentaban cotidianamente en las ciudades italianas medievales cuyo origen está en los fuertes empréstitos que concertaban los gobiernos de las ciudades. Como los gobiernos sintieron la imposibilidad material de poder honrar los excesivos intereses buscaron la forma de conceder a sus acreedores el derecho de cobrar los impuestos. Para hacer efectiva esta facultad las asociaciones de acreedores crearon las sociedades llamadas mons, massa, maona, cuyo capital estaba constituido por la suma prestada. Como ejemplo de esta clase de sociedades tenemos a la Casa di S. Giorgio, en Génova, la que tenía dos notas que caracterizan a la Sociedad Anónima moderna: la responsabilidad limitada, que era igual al importe del crédito de cada uno y la división del capital en partes iguales y transmisibles (loca loca comperarum) es decir, posible de ser negociados en algunos casos.

Destaca el jurista ya citado que el espíritu de lucha y carácter corporativo de la asociación, que al principio faltaban, se perciben ya claramente a principios del siglo XV, cuando la Casa di S. Giorgio se transforma en Banco di S. Giorgio en el momento en que comienza a realizar actividades bancarias lucrativas (1407). Adoptando una figura similar al Banco di S. Giorgio, se crea en Milán el Banco di S. Ambrogio en el año 1592, que posteriormente se transforma en Banco por Acciones el año 1598, obteniendo en sus actividades gran prestigio empresarial por la trascendencia de las operaciones financieras que realizaba.

Algunos tratadistas señalan que el origen de la S.A. se encuentra en los actos mercantiles que se realizaban en Holanda con este carácter. Fueron los navegantes y comerciantes holandeses los que dieron nacimiento a este 
Vicente Rodolfo Walde Jáuregui - El capital social en las diversas formas de la sociedad anónima, los principios y las diversas funciones que cumple tanto externa como internamente en estas

nuevo tipo de desarrollo empresarial con aportes exclusivamente dinerarios, convirtiéndose los desplazamientos patrimoniales a favor de la empresa en entes mercantiles más importantes que los elementos personales que la impulsaban; siendo los elementos personales las notas distintivas más singulares en la empresa individual o en la empresa colectiva.

“Efectivamente, en los puertos del Mar del Norte y del Atlántico aparecieron compañías mercantiles, que tienen su origen en la lucha por las colonias de ultramar entre las grandes potencias marítimas del siglo XVII, y en las que se perciben con absoluta nitidez los rasgos de las modernas s.a. Instrumento de esta lucha fueron las asociaciones de armadores de buques o sociedades navales (Reedereien), de cuya agrupación nacieron las grandes compañías coloniales, que constituyen el antecedente más directo de nuestra moderna sociedad por acciones. La primera compañía de esta clase, la Compañía de las Indias Orientales, es creada en 20 de marzo de 1602, y a partir de esta fecha se sucede la fundación de otras grandes compañías similares: "Compañía inglesa de las Indias Orientales" (1612), "Compañía sueca", fundada en 1615 por el rey Gustavo Adolfo; "Compañía danesa de las Indias Orientales" (1616), “Compañía holandesa de las Indias Occidentales" (1621) y “Compañía francesa de las Indias Occidentales y Orientales" (1664). El uso de la palabra "acción" se remonta a 1606" 2 .

Nos reseña el maestro Garrigues que si buscamos los antecedentes en España de este tipo de Empresa Mercantil, a inicios del siglo XVIII se dictaron algunos decretos para la creación de las Compañías Mercantiles que se dedicaban a realizar negocios en las Indias Occidentales como en las Orientales, como ejemplo tenemos la Compañía fundada en Guipúzcoa en 1728, que comerciaba con la ciudad de Caracas y la Gran Compañía de Cádiz, fundada por Felipe $\mathrm{V}$ a la que se le dio el nombre de Real Compañía de Filipinas.

Se advirtió que estas importantes compañías coloniales son el resultado de la mixturación de la antigua commenda y las Asociaciones Navieras. También tenemos el caso de las Grandes compañías Coloniales Holandesas y el Banco de San Jorge en Génova que son dos ejemplos paralelos de expansión de las empresas mercantiles en esa época y además son el antecedente más significativo de las Sociedades Mercantiles contemporáneas, pero con una mayor ingerencia de las Compañías Holandesas que aquellas que se desarrollaron en Italia.

$2 \quad$ Ibid., p. 410 . 
Vicente Rodolfo Walde Jáuregui - El capital social en las diversas formas de la sociedad anónima, los principios y las diversas funciones que cumple tanto externa como internamente en estas

\section{SISTEMAS LEGISLATIVOS DE LA ÉPOCA}

En la época funcionaban los sistemas legislativos que estaban vinculados con la evolución de la Sociedad Anónima, distinguiéndose tres periodos con diversos sistemas jurídicos que son a saber:

a) Sistema del "octroi" (acto de incorporación y concesión de derechos de soberanía). Los códigos de los siglos XVII y XVIII no contienen una reglamentación de la S.A. Los rasgos originales de las compañías holandesas de principios del siglo XVII los vemos expresados en las grandes compañías que se fundaron en forma sucesiva en toda Europa.

Una nota distintiva de ellas era la absoluta dependencia del Estado (que o bien dota a la compañía de su estatuto en el mismo Decreto de creación o permite a los interesados que lo formulen ajustándose a las bases del octroi y la desigualdad de derechos que se da en el seno de la misma sociedad.

El Estado crea la sociedad mediante el sistema del octroi (acto de incorporación y de concesión de derechos de soberanía). Como filial suya que es, el Estado se reserva una constante intervención y tutela en la vida del nuevo organismo, al que, por otra parte, concede privilegios incompatibles con el concepto puro de la sociedad mercantil privada.

Puede advertirse que la responsabilidad derivada por el monto de las acciones que se suscriben no estaba nítidamente establecida, sin embargo en muchos casos se aplicaban este tipo de responsabilidad para lograr su convalidación y reconocimiento en el Primer Código de Comercio en Europa que fue el primer Código de Comercio Francés 1807

Debe destacarse aquí la oposición entre el sistema continental y el sistema inglés. En el primero, la existencia y el funcionamiento de la compañía están en manos del poder público. Es significativo el acto de Luis XVI de Francia disolviendo en 1674 la Compañía de las Indias Occidentales y apoderándose de las posesiones coloniales de la sociedad. En el Derecho inglés hay un mayor respeto hacia la autonomía de los socios y sus derechos en la sociedad. La concesión otorgada a la Joint Stock Company se limita al acto de incorporación y a los privilegios jurídico-públicos.

b) Sistema de la Autorización Gubernativa. Al desaparecer la monarquía se diluye el sistema de concesión real. El sistema francés en consecuencia instaura el principio de la libertad industrial, estableciendo el régimen de la 
Vicente Rodolfo Walde Jáuregui - El capital social en las diversas formas de la sociedad anónima, los principios y las diversas funciones que cumple tanto externa como internamente en estas

necesidad de una autorización previa de gobierno para crear las sociedades, las que reguló mediante el reglamento de autorización pública que resulta aplicable en esa época, cuyo carácter no era permanente, porque en cualquier momento se podía invocar.

En España se ve clara la repercusión de la legislación francesa en el ordenamiento legal de la S.A. El Codeco de 1829 exigía la aprobación por el Tribunal de comercio de las escrituras y reglamentos de la compañía, instaurando un sistema de intervención judicial menos riguroso que el Código Francés.

Con la ley del 19 de octubre de 1869 la legislación española se aparta decididamente del sistema francés de la autorización, declarando libre la creación de todos los Bancos y sociedades que tuvieran por objeto cualquier empresa industrial o de comercio.

Destacándose por el maestro español además que en su país la legislación de carácter fiscal, inspirada en la "defensa contra las combinaciones financieras en la aportación de capitales que por su carácter marcadamente inflacionario eran contrarias a la política de saneamiento monetario", introdujo de nuevo entre nosotros el sistema de la autorización gubernativa previa, que en este caso había de dar el ministro de Hacienda, para fundar sociedades de más de cinco millones de pesetas de capital y para ampliarlo en las sociedades que tuvieran ya este capital (ley del 19 de setiembre de 1942, Orden del 23 de octubre del mismo año, Orden del 28 de febrero de 1947). Estas disposiciones fueron derogadas al entrar en vigor la Ley de Sociedades anónimas del 17 de julio de 1951.

c) Sistema de las Disposiciones Normativas. Este sistema se crea por la ley francesa del 24 de julio de 1867, que estableció que para crear la Sociedad Anónima no se requería la autorización o comisión del Estado, sino tan solo la observación de ciertas normas coactivas de suscripción y aporte de capital, así como de aporte de bienes in natura. Fue esta ley en su momento un significativo avance en la legislación y en la doctrina relacionada con la Sociedad Anónima.

El Codeco español vigente hay que situarlo dentro del sistema de las disposiciones normativas, ya que dedica dos secciones $\left(4 .{ }^{\mathrm{a}}\right.$ y $5 .{ }^{\mathrm{a}} \mathrm{del}$ Tit. I del Libro II) a regular las compañías anónimas y sus acciones sin exigir para su fundación el requisito previo de una autorización judicial o gubernativa. Pero esta reglamentación tiene en su mayor parte carácter dispositivo (v. art. 121) y 
Vicente Rodolfo Walde Jáuregui - El capital social en las diversas formas de la sociedad anónima, los principios y las diversas funciones que cumple tanto externa como internamente en estas

es, además, escasísima, hasta el punto que puede decirse que nuestro Código no nos ofrecía una reglamentación de la S.A., sino más bien la base para una reglamentación de tal sociedad ${ }^{3}$.

La "Ley sobre régimen jurídico de Sociedades Anónimas" del 17 de julio de 1951, derogando las disposiciones del Codeco relativas a esta forma social, regula la S.A. en forma predominantemente coactiva, representando la incorporación del Derecho Español al sistema de las disposiciones normativas.

Se considera, asimismo, que existe una evolución conceptual, dado que la organización aristocrática, encarnada en la desigualdad de derechos y en la preponderancia de los grandes accionistas y de los directores de la sociedad, desaparece con el sistema francés de las disposiciones normativas. Al compás de la evolución política, la s.a. no solo se libera de la intervención estatal, sino que se hace democrática. Pero hacia mucho tiempo que los hechos no se correspondían con las palabras de la ley. Al derecho de acciones legislado se contraponía un derecho de acciones vivo.

\section{LA SOCIEDAD ANÓNIMA Y SU VINCULACIÓN ESTATAL, PATRIMONIO Y CAPITAL SOCIAL}

La Sociedad Anónima que hemos referido con indesligable vinculación estatal actualmente diversifica su influencia y se desarrolla con gran esplendor en el sector privado, pero también en una forma adecuada en el sector estatal para la realización de determinados negocios y se vincula necesariamente con el desarrollo de la economía en los diversos países donde se utiliza su forma jurídica para realizar y desarrollar importantes negocios.

Lo evidente es que la Sociedad Anónima es una sociedad eminentemente de capitales y no puede concebirse esta forma societaria desvinculándola del elemento capitalista.

El propio Garrigues al respecto nos dirá: La S.A. es, puede decirse, un capital con categoría de persona jurídica. El concepto de capital ilumina la esencia de la S.A.; para explicarlo hay que partir de la distinción entre capital y patrimonio social.

a) Patrimonio es el conjunto efectivo de bienes de la sociedad en un momento determinado. Su cuantía está sometida a las mismas oscilaciones que el

$3 \quad$ Ibid., p. 412. 
Vicente Rodolfo Walde Jáuregui - El capital social en las diversas formas de la sociedad anónima, los principios y las diversas funciones que cumple tanto externa como internamente en estas

patrimonio de una persona individual: aumenta si la industria es próspera, disminuye en el caso contrario. En el primer caso, el patrimonio activo (dinero, cosas, derechos, valores económicos de toda clase) será superior al pasivo (deudas). En el segundo caso ocurrirá lo contrario ${ }^{4}$.

b) El Capital Social es, por el contrario, solamente una cifra permanente de la contabilidad, que no necesita corresponder a un equivalente patrimonial efectivo. Indica esa cifra el patrimonio que debe existir, no el que efectivamente existe.

La cifra de capital es un elemento esencial al constituirse la sociedad. Al efecto la expresión del capital social en la escritura de constitución constituye la declaración de que los socios han aportado una cuantía de capital o se han comprometido a aportarlo en su momento en no menos del $25 \%$ de lo ofrecido y la sociedad es responsable de su existencia. La ley que la regula se orienta en establecer que es indispensable que la sociedad tenga un patrimonio igual al de la cifra del capital social; para el efecto obligan a los socios a que cumplan con entregar la totalidad del capital que han suscrito, debiendo los gestores de la sociedad iniciar una comprobación estricta de que esto se esta cumpliendo; una forma de logarlo esta en la prohibición de que la sociedad brinde muchas facilidades para restituirle sus aportaciones a los accionistas, regulando la redención del capital con ciertas limitaciones y exigencias formales para su ejecución y sancionando severamente su infracción.

Esto no escapa de las vicisitudes que pueden presentarse en el ejercicio de la actividad societaria, cuyo éxito en su aplicación dependerá de las habilidades de quienes asuman la responsabilidad de la gestión social.

De todo esto se puede desprender que el capital y el patrimonio social -que legal y técnicamente deben ser iguales al constituirse la sociedad (si los socios no realizaron íntegramente su aportación, la sociedad tendrá contra ellos el crédito correspondiente y este crédito es ya patrimonio activo)-, pueden ser de cuantía distinta incluso desde el primer momento (v. gr.: si las acciones se emiten sobre la par) y lo son, normalmente, en cuanto la sociedad empieza a funcionar, puesto que la ganancia o la pérdida hará aumentar o disminuir la cifra del patrimonio social, quedando siempre intacta la del capital. La cifra del capital es una línea cerrada o círculo ideal trazado en el activo de la sociedad, que no acota bienes determinados, pero que impone a la sociedad la obligación de tenerlo siempre cubierto con bienes equivalentes a aquella

$4 \quad$ Ibid., p. 437. 
Vicente Rodolfo Walde Jáuregui - El capital social en las diversas formas de la sociedad anónima, los principios y las diversas funciones que cumple tanto externa como internamente en estas

cifra. Todo lo que exceda de este círculo puede ser distribuido entre los socios. Pero así como la línea del capital es fija (mientras no se modifique con las formalidades legales), la línea del patrimonio es, por esencia, movible. Por ello, aunque inicialmente coinciden una y otra, en cuanto la sociedad empieza a funcionar la línea del patrimonio empieza a moverse. Si los negocios van mal, en ese caso se ve clara la función del capital como cifra de retención: la sociedad no podrá repartir dividendos a sus accionistas mientras la línea del patrimonio no vuelva a coincidir con el capital.

\section{EL CAPITAL SOCIAL, ALTERNATIVAS Y PRINCIPIOS}

Cuando recién se inicia la sociedad puede acontecer que el patrimonio social sea superior al capital social si las acciones se han emitido sobre la par o si las acciones relacionadas con los bienes no dinerarios están por debajo de su valor real.

Como ejemplos podemos señalar el siguiente caso: Una sociedad con grandes expectativas de éxito se constituye con un capital de un millón de soles, dividido en mil acciones de mil soles. Pero en el mercado se paga por cada acción mil cien soles. En este caso esa sociedad en sus comienzos tendrá un capital de un millón de soles y un patrimonio de un millón cien mil soles. Lo propio ocurrirá si los bienes inmuebles aportados se valoran en cien mil soles menos de su valor real. Y la misma diferencia, favorable a los acreedores, existirá entre capital y patrimonio social cuando al final del primer año los bienes de la sociedad hayan experimentado una plus valía de cien mil soles; esto debe entenderse como la prima de capital que se adquiere en el mayor valor de las acciones como consecuencia del desarrollo de sus actividades negociales influencias en gran medida por los fondos de reserva de la sociedad.

Por el contrario, puede ocurrir -que aunque no sea lo normal y aunque las leyes contengan disposiciones para evitarlo- que desde el comienzo sea inferior el patrimonio al capital social. Tal ocurrirá cuando las aportaciones en especie se hayan valorado con exageración. Ejemplo: se aprecia una casa aportada en cien mil soles más de lo que vale. Tendríamos entonces: Capital social= un millón de soles. Patrimonio social= novecientos mil soles. El mensaje en este caso para los acreedores de la sociedad es equívoco porque cuentan con un patrimonio de garantía equivalente a un millón de soles. De aquí los preceptos reguladores de la tasación cuando las aportaciones de los socios no son en dinero, así como la prohibición legal de la emisión de acciones por bajo de la par, común a la mayoría de las legislaciones. Durante la vida de la sociedad es inevitable que, a virtud de pérdidas, el patrimonio social quede 
Vicente Rodolfo Walde Jáuregui - El capital social en las diversas formas de la sociedad anónima, los principios y las diversas funciones que cumple tanto externa como internamente en estas

por debajo de la cifra del capital. Lo único que los acreedores pueden exigir es conocer la verdadera situación por medio de balances veraces.

Existen en la doctrina reconocidos principios que regulan el Capital Social y que son dos principios clásicos que completan la defensa del capital de la sociedad por acciones, con los cuales se le pretende dar una protección adecuada a los negocios que se realice:

$1^{\circ}$ El Principio de la determinación y unidad del capital social. Es el supuesto lógico de la defensa del capital. La S.A. ha de nacer con un capital determinado y único. La fijación del capital social es una de las menciones de la escritura de constitución. En la S.A. el capital no es solo funcional, como en las demás sociedades, sino fundacional. No podrá constituirse sociedad alguna que no tenga su capital suscrito totalmente y desembolsado en una cuarta parte, por lo menos.

$2^{\circ}$ El Principio de la Estabilidad del Capital. El que debe entenderse que exige que la cifra del capital no puede ser libremente alterada, ya que todo aumento de la misma significaría un engaño para los acreedores si no va acompañado del correlativo aumento en el patrimonio social; toda disminución implica la posibilidad de reducir en la misma cuantía el patrimonio, con la consiguiente disminución de la garantía para los acreedores. Pero durante la vida de la sociedad puede presentarse la necesidad de dinero y no querer obtenerlo a titulo de préstamo; o puede ser conveniente restablecer el equilibrio entre el capital y el patrimonio, reducido por consecuencia de pérdidas. A estos supuestos principales corresponden, respectivamente, los procedimientos de aumento y de reducción del capital social, que son otras tantas excepciones al principio de la estabilidad en el sentido expuesto.

\section{AUMENTO Y REDUCCIÓN DEL CAPITAL SOCIAL}

Durante la vigencia de la Sociedad, por los requerimientos del negocio que realiza, puede requerirse de mayores recursos en cuyo caso puede obtenerlos acudiendo a la figura del aumento de capital que se da en ciertas ocasiones con la emisión de obligaciones, pero puede haber un aumento de capital cuando se convierten las reservas y las primas de las acciones en acciones, en cuyo caso no hay un nuevo recurso patrimonial en la sociedad. Para el efecto se debe modificar los estatutos que tomarán en cuenta como consecuencia de ello lo que ocurrió en el acto fundacional en el que existe una referencia histórica del monto del capital aportado. 
Vicente Rodolfo Walde Jáuregui - El capital social en las diversas formas de la sociedad anónima, los principios y las diversas funciones que cumple tanto externa como internamente en estas

Cuando nos referimos al aumento de capital deben considerarse dos aspectos:

a) La toma del acuerdo para aumentar el capital; esta prerrogativa le corresponde exclusivamente a la Junta General de Accionistas, requiriéndose un quórum calificado para adoptar el acuerdo y una vez que se apruebe deberá ser inscrito en los registros públicos donde aparece registrada la sociedad.

b) La ejecución del acuerdo; que deberá realizarse en los mismos términos en los que se adoptó el acuerdo de aumento del capital social, respetándose las normas del estatuto que rige la vida de la sociedad.

Al decidirse elevar su capital una sociedad puede proponerse, o bien aumentar efectivamente su patrimonio productivo mediante la aportación de nuevos elementos patrimoniales (aumento efectivo), o bien elevar sencillamente la cifra del capital, pero sin necesidad de ingresar nuevos elementos patrimoniales, o sea mediante un simple traspaso de cuentas en el balance (aumento puramente contable). Se señala al respecto que "el contravalor de las nuevas acciones o del aumento del valor nominal de las existentes, podrá consistir tanto en nuevas aportaciones al patrimonio social, como en la transformación de reservas o de plusvalías de este patrimonio, o en la conversión de obligaciones en acciones". En este precepto legal están incluidos tanto el supuesto de aumento efectivo como el supuesto del aumento puramente contable del capital.

\section{MOTIVACIONES JURÍDICAS E HISTÓRICAS DE LA SOCIEDAD ANÓNIMA EN EL DERECHO COMPARADO Y SUS RELACIONES CON LA LEGISLACIÓN INTERNA}

Como ha quedado establecido en el desarrollo histórico se cumple el proceso dialéctico de la estructuración de las Sociedades Anónimas, movilizándose a través de ellas grandes cantidades de capital porque el objeto social que motivaba esta clase de sociedad era de gran envergadura; así tenemos por ejemplo que la conquista de los nuevos territorios de las Indias Orientales se hizo a través de las importantes empresas de navegación que adoptaban la forma de las Sociedades Anónimas las cuales para su existencia requerían contar con una ley que autorizase su creación y funcionamiento.

El profesor sanmarquino, Ulises Montoya Manfredi nos ilustraba en sus clases del curso de Derecho Comercial I, sobre Sociedades Mercantiles, señalándonos 
Vicente Rodolfo Walde Jáuregui - El capital social en las diversas formas de la sociedad anónima, los principios y las diversas funciones que cumple tanto externa como internamente en estas

que el antecedente más antiguo de la Sociedad Comercial lo encontrábamos en las caravanas de los comerciantes, en las que se reunían para realizar significativos desplazamientos de sus mercaderías a grandes distancias; al unirse o agruparse generaban la concentración de importantes cantidades de capital, la cual de resultar exitosa en los negocios les proporcionaba pingues - ganancias; esta unión mercantil al mismo tiempo les otorgaba un marco de protección frente a las acechanzas de sus singulares travesías.

Como ya lo hemos mencionado esta reseña histórica de la sociedad comercial cambia con el tiempo facilitando los negocios mercantiles de su época liberalizándose la fundación de las Sociedades Anónimas, que no requerían de una ley autoritativa sino que era indispensable el animus o la afeccio societatis y la puesta en común de bienes y servicios para generar ganancias; así lo estatuyó el primer Código de Comercio en el mundo, que fue el Código de Comercio Francés de 1807, que es seguido por el Código de Comercio Español de 1829 y el Código de Comercio Alemán en fecha posterior.

El propio nombre de la Sociedad Anónima viene siendo discutida en la comunidad mercantil -como lo señala el profesor italiano Tullio Ascarelli en su obra "Panoramas del Derecho Comercial"-, quien sostiene que el nombre correcto de esta forma societaria no debiera ser Sociedad Anónima, sino "Sociedad Comercial por Acciones"; con esta tesis estamos de acuerdo, máxime si en nuestro país existe una exigencia ineludible para esta clase de sociedades en el sentido de que las acciones que representan el capital social deben ser emitidas con carácter nominativo (identificando el nombre del socio) y no con la cláusula al Portador (es decir legitimando a su detentador o poseedor sin que aparezca su nombre en dicho documento).

\section{SOCIEDAD ANÓNIMA - ENTE EMINENTEMENTE DE CAPITALES}

Resulta trascendental destacar que en las Sociedades Anónimas lo más importante es el capital aportado atendiendo al tipo de responsabilidad que adquieren los socios al momento de constituir la sociedad, porque estos frente a las alternativas de responsabilidad objetiva que pueda presentarse en el desarrollo del negocio social, solo arriesgan como garantía de ellas el monto del capital dinerario o de bienes in natura que hubieran aportado, es decir que el acervo patrimonial particular no aportado no tiene porque responder por las deudas o cargas sociales que resulten del negocio, como si ocurre por ejemplo en las sociedades colectivas o con los socios colectivos de las Sociedades en Comandita o de alguna manera en la subsidiaria responsabilidad de los socios en las Sociedades Civiles Ordinarias. 
Vicente Rodolfo Walde Jáuregui - El capital social en las diversas formas de la sociedad anónima, los principios y las diversas funciones que cumple tanto externa como internamente en estas

No cabe duda que el monto del capital social nos ha de llevar necesariamente en el Sistema Societario Peruano, de las Sociedades Anónimas a la aplicación necesaria del art. 82 de la Ley 26887, que estatuye "Las acciones representan partes alícuotas del capital, todas tienen el mismo valor nominal y dan derecho a un voto, con la excepción prevista en el articulo $164^{\circ}$ y las demás contempladas en la presente ley".

Existen en consecuencia un correlato de proporcionabilidad entre los bienes que se aportan y el número de acciones que se reparten en los socios, a los que les corresponde el derecho de establecer cual debe de ser el valor nominal de las acciones.

Nuestro Sistema recogido en la Ley General de Sociedades vigente, establece una pluralidad de bienes que pueden ser aportados; resultando importante al respecto no solo la naturaleza de los bienes que se aportan sino la forma jurídica válida para que se produzca el aporte a fin de que genere el efecto deseado por el aportante de convertirse en socio y la Sociedad en dueña de los bienes aportados. Entre los bienes que se aportan señalaremos los siguientes: el dinero, los bienes muebles y los bienes inmuebles, las patentes de invención, los royalty, contratos de know how, los derechos de uso y usufructo, los títulos valores con las cláusulas al portador, a la orden o nominativos, prohibiéndose que puedan aportarse los servicios o industria entendiéndose esta limitación sustentada en el hecho de que la Sociedad Anónima es una sociedad eminentemente de capitales. Al respecto nosotros tenemos una apreciación distinta, consideramos que en algunos casos, con determinados condicionamientos y formalidades, el socio industrial puede participar en la sociedad anónima otorgándole desde el principio un anticipo de retribución económica, esa a la que tiene derecho con la cual se convertiría en un socio capitalista y confiriéndole algunas obligaciones dentro del negocio societario, desarrollándose un esquema del capital con estructura mixta en la calidad de accionista o también en algunos casos una condición singularísima para el efecto. Refuerza la tesis de la incorporación el hecho cierto de que este socio tiene obligaciones inmanentes que pueden contribuir al mejor logro de las actividades negociables de la empresa mercantil corporativa ${ }^{5}$.

\section{EL CAPITAL DE LA SOCIEDAD}

Los aportes de los socios son los que han de constituir el capital social de la empresa mercantil una vez que la sociedad se constituye e inicia sus

5 Otros aspectos de esta incorporación los hemos desarrollado en un artículo que hemos publicado en la revista VOZ IURIS de la USMP y no es del caso profundizar en ellos en el tema que estamos desarrollando. 
Vicente Rodolfo Walde Jáuregui - El capital social en las diversas formas de la sociedad anónima, los principios y las diversas funciones que cumple tanto externa como internamente en estas

actividades; la cifra del capital que constituye parte del patrimonio de la sociedad por la naturaleza del negocio puede ser que se encuentre en algún momento a la par, sobre la par y bajo la par; esto por supuesto influirá en el desarrollo de la actividad negocial de la empresa y puede contribuir al éxito o en algunos casos causarle un detrimento significativo al desarrollo futuro de la sociedad. En algunas legislaciones, como por ejemplo la ley española, se tiene unas limitaciones legales para señalar un capital autorizado de tal manera que, desde el punto de vista de la cifra, si se pretende elevar el capital no podrá superar la mitad del capital nominal de la sociedad en el momento de la autorización, la misma que no puede prolongarse más allá de 5 años que comenzarán a contarse desde el momento de la fundación de la sociedad o de la modificación de los estatutos, debiendo tomarse en cuenta también a qué clase de acciones se les autoriza la elevación, que en la mayoría de los casos es para acciones ordinarias. En estos casos la Junta General pueden fijar las condiciones de las futuras emisiones referidas en las aportaciones de dinero o en bienes, así como en los derechos de suscripción preferente; el tema de la autorización del capital puede tener 2 aspectos o una doble forma, se puede dar de acuerdo con la permisibilidad que regulen los estatutos históricos de la sociedad y también conforme al acuerdo de modificación de los estatutos, para que en ellos conste la concesión de la facultad autoritativa que debe señalar oportunidades, cuantías, formas, y periodos del aumento del capital. $\mathrm{Al}$ respecto debemos señalar que en la doctrina surge el concepto de Capital Nominal al cual debe considerarse no solo como capital social originario sino el total que haya sido objeto de uno o de varios aumentos.

Refiriéndonos a las modalidades de aplicación para el capital autorizado se reconoce sustancialmente dos: una esta dada por la modificación de la cláusula estatuaria en la que se consagra el enunciado de la cifra de capital por cuyo mérito se deja sin efecto la autorización anterior; pero también puede hacerse mediante una autorización del estatuto mediante las disposiciones transitorias, con una autorización expresa para hacerlo así.

\section{DESARROLLO DE LAS AUTORIZACIONES Y PLAZOS DEL AUMENTO DEL CAPITAL EN EL DERECHO COMPARADO}

En la ley alemana se dispone un plazo máximo de 5 años a partir de la inscripción de la sociedad para que los estatutos autoricen a la dirección de la empresa el aumento del capital social hasta una cifra nominal determinada a través de la emisión de nuevas acciones desembolsadas. La autorización podrá concederse con ocasión de la modificación de estatutos para un plazo máximo de 5 años a partir de la inscripción de dicha modificación; se señala 
Vicente Rodolfo Walde Jáuregui - El capital social en las diversas formas de la sociedad anónima, los principios y las diversas funciones que cumple tanto externa como internamente en estas

en la ley germana que la cifra del aumento no podrá ser superior a la mitad del capital social existente en el momento de la autorización.

En el Código Civil Peruano se precisa que en el acto constitutivo se puede investir a los administradores de las prerrogativas del aumento de capital por una o varias veces a través de la emisión de acciones ordinarias hasta una suma determinada por el periodo máximo de un año de la fecha de inscripción de la sociedad; esta facultad se puede realizar también a través de la modificación del acto constitutivo durante la vida de la sociedad por el periodo máximo de un año desde la fecha del acuerdo.

En la Ley Francesa se establece que la Asamblea General puede delegar en el Consejo de Administración o en el Directorio, según los casos, los poderes necesarios para realizar el aumento de capital por una o varias veces fijando las modalidades del aumento la formalización de la operación y proceder a la modificación correlativa de los estatutos. Se estatuye que además se tendrá por no puesta cualquier cláusula estatutaria que confiera al Consejo de Administración o al Directorio, según los casos, la facultad de decidir el aumento de capital.

\section{EL ACUERDO DE REDUCCIÓN DE LA CIFRA DEL CAPITAL}

Debemos afirmar que el capital por decisión o por mandato de la ley puede reducirse -y en este caso es una disminución de la cifra abstracta del capital social- conforme a los requisitos establecidos por la ley. Esta reducción se puede proponer con distintos fines económicos puede ser en parte para equilibrar la cifra de capital y patrimonio en los casos en que pudieran existir perdidas sociales contabilizadas o también para hacer posible la devolución a los accionistas de una parte del capital, como también para transformar una parte del capital en reservas. No existe problema para que se reduzca el capital combinándolo con otras operaciones de aumento. En el régimen legal que permite la reducción del capital hay dos fines fundamentales como son: la protección de los acreedores en la sociedad y la búsqueda de la equidad en la reducción en la relación de la sociedad con los accionistas y la relación de estos entre si.

Se pueden distinguir 3 clases de reducción de capital:

a) Hay una reducción de capital efectiva con devolución de aportaciones o no.

b) La exigencia de dividendos pasivos, la reducción de capital por causas de pérdidas sociales. 
Vicente Rodolfo Walde Jáuregui - El capital social en las diversas formas de la sociedad anónima, los principios y las diversas funciones que cumple tanto externa como internamente en estas

c) La reducción con cargos a beneficios o reservas libres.

La reducción de capital es una modificación estatutaria que debe ser adoptada con los requisitos y solemnidades que establezca la ley. Sin embargo, existen reducciones de capital que se realizan sin la necesidad del acuerdo societario de la Junta General de Accionistas; estas se pueden dar en los casos en que se traten de aportaciones no dinerarias o sobre falta de desembolso de acciones, así como también sobre el derecho de separación de accionistas.

El profesor español Ángel Velasco Alonso ${ }^{6}$ nos ilustra respecto de la reducción de capital sosteniendo que en el Derecho Comparado "En cuanto al Código Civil Italiano, dice el artículo 2445 que la reducción del capital, cuando éste resulta sobrante para la realización del objeto social, podrá tener lugar, bien mediante la no exigencia de dividendos pasivos, bien mediante el reembolso del capital a los socios, dentro de los límites de los artículos 2327 y 2412. El acuerdo podrá ser ejecutado si dentro de los tres meses siguientes a la fecha de la inscripción en el registro de la empresa ningún acreedor social anterior a la inscripción hubiere hecho oposición. El Tribunal, no obstante, podrá disponer de la reducción que lleve a efecto, previa la presentación de parte de la sociedad de una garantía adecuada".

Por último, la Ley Francesa expresa en el artículo 2445 que la reducción de capital será autorizada o acordada por la asamblea general extraordinaria, que podrá delegar en el Consejo de Administración o en el Directorio, según el caso, todas las facultades para realizarla. En ningún caso se quebrantará el principio de igualdad de los accionistas. El proyecto de reducción será comunicado a los comisarios de cuentas en el plazo que se fije por Decreto. La asamblea acordará sobre el informe de los comisarios relativo a su apreclaración de las causas y condiciones de la reducción. Cuando el Consejo de Administración o el Directorio, según el caso, realice la operación por delegación de la asamblea general, dispondrá el proceso verbal sometido a publicidad y lo necesario para la modificación de los estatutos.

\section{LA GARANTÍA DE LOS ACREEDORES}

Otro tema que resulta ser importante en el análisis del capital de la Sociedad Anónima es el relativo al respaldo de la acreencia, es decir la forma como se garantizan los créditos y por ello ha de tenerse en cuenta que "Ningún acuerdo de reducción del capital que implique restitución de sus aportaciones

6 Velasco AlOnSO, Ángel. La Ley de Sociedades Anónimas. Quinta Edición. Caracas-Madrid: Editoriales de Derecho Reunidas, p. 529. 
Vicente Rodolfo Walde Jáuregui - El capital social en las diversas formas de la sociedad anónima, los principios y las diversas funciones que cumple tanto externa como internamente en estas

a los accionistas, o condonación de dividendos pasivos, podrá llevarse a efecto antes de que transcurra el plazo prudencial que puede ser tres meses, a contar de la fecha del último acuerdo, que en algunas legislaciones se establece que deberá ser publicado por tres veces en el "Boletín Oficial del Estado" y en tres periódicos de los de mayor circulación del lugar en que la Sociedad tenga su domicilio. Durante este plazo los acreedores ordinarios pueden oponerse a la ejecución del acuerdo de reducción si sus créditos no son satisfechos o la Sociedad no presta garantía. Será nulo todo pago o liberación de dividendos pasivos que se realice antes de transcurrir el plazo de tres meses, o, a pesar de la oposición entablada, en tiempo y forma por cualquier acreedor.

\section{PROTECCIÓN DE LOS ACREEDORES}

Existen también al respecto un conjunto de medidas de protección que otorga a los acreedores, el derecho de oposición, se concede a los acreedores ${ }^{7}$ un plazo para oponerse a la ejecución del acuerdo de reducción, en el caso de que sus créditos no sean satisfechos, o la sociedad no presta garantía suficiente, a juicio de los acreedores. Por otra parte, la Ley prohíbe todo pago o liberación de dividendos pasivos dentro de aquel plazo, o a pesar de la oposición formulada por cualquier acreedor.

En consecuencia, el acuerdo quedará en suspenso: a) Durante el tiempo de publicación de los anuncios. b) Durante los tres meses siguientes a la fecha de publicación del último anuncio. c) Durante todo el tiempo que dure la oposición de cualquier acreedor entablada en tiempo y forma. Los tres meses deben comenzar a contarse a partir de la fecha de aparición del último anuncio en cualquier clase de publicación.

El derecho de oposición corresponde a los acreedores ordinarios. No son acreedores ordinarios los hipotecarios o pignoraticios. Tampoco están protegidos en el sistema de la Ley los acreedores cuyos créditos se hubieren generado durante el plazo de suspensión del acuerdo. Los acreedores litigiosos deben entenderse protegidos. Lo mismo los administradores que ostenten créditos contra la sociedad.

\section{DERECHO DE OPOSICIÓN}

La oposición de los acreedores subsiste mientras sus créditos no sean satisfechos o garantizados. La oposición puede ser formulada judicial o

\footnotetext{
$7 \quad$ Ibid., p. 532.
} 
Vicente Rodolfo Walde Jáuregui - El capital social en las diversas formas de la sociedad anónima, los principios y las diversas funciones que cumple tanto externa como internamente en estas

extrajudicialmente, dentro del plazo de tres meses, contados a partir de la fecha de publicación del último anuncio. Nada se opone a la realización de un convenio colectivo con los acreedores. La petición judicial del pago o afianzamiento de los créditos puede solicitarse por los trámites de los actos de jurisdicción voluntaria. Transcurrido el plazo legal sin dar satisfacción a la oposición, no podrá ejecutarse el acuerdo de reducción.

\section{DERECHO A LA GARANTÍA DE LOS CRÉDITOS}

Toda clase de garantía, sea de índole personal (fianza civil o afianzamiento mercantil), sea de índole real (hipoteca o prenda), esté o no registrada como forma típica de garantía en los códigos, y se preste por la sociedad, por sus administradores o por extraños, podrá servir para hacer posible la ejecución del acuerdo, si el acreedor la acepta como buena y suficiente. Este derecho debe estimarse que no existe en casos de quiebra o suspensión de pagos de la sociedad, porque para estos casos hay una tutela legal que dispensa a la masa de bienes del deudor en uno y otro procedimiento.

\section{NULIDAD DE PAGOS Y LIBERACIÓN DE DIVIDENDOS PASIVOS}

Se ha propuesto en el sistema societario como garantía sancionadora la nulidad de los pagos realizados a los accionistas en concepto de devolución de aportaciones, y de los actos de liberación de dividendos pasivos, que se tendrán por inexistentes o no realizados. Todo ello se entiende sin perjuicio de la responsabilidad en que pueden incurrir los administradores de la sociedad. No tienen la consideración de pagos prohibidos la entrega de dividendos a los accionistas. A menos que se trate de dividendos ficticios.

En el Código Suizo las Garantías de los acreedores.- Acordada la reducción de capital por la asamblea general, la administración publicará el acuerdo por tres veces en la "Hoja Oficial Suiza de Comercio" y en la forma prescrita por los estatutos, para conocimiento de los acreedores, los cuales, dentro de los dos meses siguientes a la fecha del último anuncio, podrán exigir el pago o la garantía de los créditos ${ }^{8}$.

Ejecución de la reducción.- La reducción de capital solo podrá ser ejecutada después del transcurso del plazo concedido a los acreedores para pedir el pago o la garantía de sus créditos, y será inscrita en el Registro Mercantil cuando se hiciere constar por documento público que las garantías de esta

8 Ibid., p. 533. 
Vicente Rodolfo Walde Jáuregui - El capital social en las diversas formas de la sociedad anónima, los principios y las diversas funciones que cumple tanto externa como internamente en estas

Sección han quedado cumplidas. El documento será incluido en el informe especial.

La Ley Alemana establece que: 1) Si no se les satisfacen los créditos, los acreedores cuyos derechos hubieren nacido antes de la publicación del acuerdo de reducción del capital, serán garantizados si lo solicitan dentro de los seis meses siguientes a la publicación. Esta publicación expresará el ejercicio de este derecho. El derecho a las garantías no se concede a los acreedores que en caso de quiebra tengan derecho a cobrar con preferencia de la masa de bienes creada por disposición de la Ley para su garantía y colocada bajo la protección del Estado. 2) Los reembolsos a los accionistas solo podrán ser efectuados después de expirado el plazo de seis meses siguientes a la fecha de publicación de la inscripción, y después de que los acreedores que lo hubiesen solicitado en tiempo hábil recibiesen 1 pago o la garantía de sus créditos. Del mismo modo los accionistas no podrán ser dispensados del pago de dividendos pasivos mientras los acreedores no hubiesen sido pagados o garantizados. 3) El derecho de los acreedores a las garantías es independiente del de los accionistas a recibir el pago de su aportación.

En cuanto a la Ley francesa, el artículo 216 estatuye que cuando la asamblea apruebe un proyecto de reducción de capital no motivado por pérdidas sociales, el representante de los obligacionistas y acreedores de fecha anterior a la del depósito en el Tribunal del acta de la asamblea, podrán oponerse a la reducción en el plazo que se fije por Decreto. La resolución judicial rechazará la oposición y ordenará el reembolso de los créditos o su afianzamiento, si la sociedad lo propone y las garantías se consideran suficientes. Las operaciones de reducción de capital no podrán comenzar durante el plazo señalado para hacer oposición.

\section{LA AGRUPACIÓN Y AMORTIZACIÓN DE TÍTULOS ACCIONARIOS EN EL SISTEMA ESPAÑOL}

Cuando la reducción implique la agrupación de acciones para su canje o estampillado, la Sociedad podrá declarar la nulidad de las acciones que no hayan sido presentadas dentro del plazo publicado al efecto en el "Boletín Oficial del Estado". Las acciones emitidas en lugar de las anuladas deberán ser inmediatamente vendidas por la Sociedad por cuenta y riesgo de los interesados y con la intervención de Agente o Corredor colegiado. El importe líquido de la venta de las acciones quedará depositado a disposición de los interesados en el Banco de España. 
Vicente Rodolfo Walde Jáuregui - El capital social en las diversas formas de la sociedad anónima, los principios y las diversas funciones que cumple tanto externa como internamente en estas

Cuando la reducción implique amortización de acciones mediante reembolso a los accionistas y la medida no afecte por igual a todas las acciones, será preciso el acuerdo de la mayoría de los accionistas interesados.

\section{Aspectos a Considerar}

Debe tomarse en consideración que si bien existe un modo especial de reducción del capital por agrupación y amortización de acciones esta debe darse en la forma propuesta, pero hay acciones que pueden eximirse de esta obligación, las acciones que no hubieran sido presentadas por el canje porque en este caso la sociedad puede proceder a su venta en vez de anularlas por cuenta y riesgo de los interesados no concurrentes a cuya disposición quedará depositado en el Banco el importe líquido de los títulos vendidos.

Requisitos a tomarse en cuenta en la Agrupación por acción:

a) Que la reducción de capital implique la agrupación de acciones para su canje o estampillado. Estas palabras de la Ley equivalen a establecer que la agrupación sea el único camino posible de la reducción. El canje equivale a una sustitución material de títulos. Tanto en este caso como en el de estampillado, será preciso que los interesados presenten sus acciones voluntariamente en el lugar y plazo señalados al efecto.

b) Publicación de anuncios en el "Diario Oficial". Los mismos anuncios pueden publicarse en los diarios elegidos por los administradores. Pero la falta de publicación de los mismos en el "Diario Oficial" determinaría la nulidad radical de la operación.

c) Declaración de nulidad de las acciones no presentadas en el lugar y plazos señalados en el anuncio. La declaración de nulidad se extenderá también a las acciones presentadas en número suficiente, a menos que la sociedad disponga de las mismas por cuenta de los titulares. La Sociedad se encuentra capacitada para declarar la Nulidad de las acciones no presentadas si es que no existe otra alternativa para su enajenación. El efecto de la declaración de nulidad de las acciones consiste en la pérdida de los derechos de socio que nazcan después de la fecha de aquélla. No será necesaria esta declaración cuando en el anuncio se hubiese hecho la advertencia de que los títulos no presentados serían anulados automáticamente por el solo hecho de la falta de presentación.

d) Venta de las acciones emitidas en lugar de las anuladas y depósito de su importe líquido en el Banco de España a disposición de los interesados. La venta se efectuará con intervención de Agente de Cambio y Bolsa o Corredor de Bolsa colegiado por cuenta y riesgo de los accionistas no concurrentes. 
Vicente Rodolfo Walde Jáuregui - El capital social en las diversas formas de la sociedad anónima, los principios y las diversas funciones que cumple tanto externa como internamente en estas

\section{AMORTIZACIÓN DE ACCIONES QUE NO AFECTE A TODAS POR IGUAL}

En el supuesto de reducción de capital con reembolso a un grupo de accionistas de sus acciones a la par, cuando debían cotizarse más bajas, se exige el acuerdo de la mayoría de los accionistas que conservan sus títulos.

Puede existir un doble acuerdo para la amortización de las acciones que se utiliza para que la reducción no afecte a todos los accionistas por igual.

\section{DERECHO COMPARADO}

El artículo 266 de la Ley Alemana dispone que: 1) Si para proceder a la reducción de capital fuese necesaria la agrupación de acciones mediante estampillado o procedimiento análogo, la sociedad podrá declarar la nulidad de las acciones que no hubieran sido presentadas. Lo mismo sucederá respecto de las acciones depositadas en cantidad insuficiente para poder ser canjeadas por las nuevas acciones y que no fuesen puestas a disposición de la sociedad para su utilización por cuenta de los interesados. 2) La invitación para la agrupación contendrá la advertencia de nulidad de las acciones no presentadas. La declaración de nulidad solo procederá si la agrupación ha sido publicada en la forma prescrita por el artículo 64, párrafo 2). La declaración de nulidad será publicada en la hoja de la sociedad. El anuncio designará con toda claridad las acciones anuladas, sin necesidad de otro aviso posterior. 3) Las acciones emitidas en sustitución de las anuladas serán vendidas inmediatamente por la sociedad por cuenta de los interesados al precio de cotización oficial, con intervención de agente, y mediante subasta pública en defecto de cotización. Si la subasta en el domicilio de la sociedad no diese resultado, podrá celebrarse en otro adecuado. Previamente se anunciará la fecha, el lugar y las acciones subastadas. Los interesados serán especialmente notificados; se podrá prescindir de este requisito en caso de imposibilidad de ejecución. El anuncio y la notificación serán realizados por lo menos dos semanas antes de la subasta. El importe de la venta será entregado a los interesados o consignado a su disposición ${ }^{9}$.

\section{LA REDUCCIÓN DEL CAPITAL EN EL DERECHO COMPARADO}

En el Código Suizo de las obligaciones se estatuye que la reducción del capital se ha de realizar sin reemplazar simultáneamente el importe de la reducción

$9 \quad$ Ibid., p. 543. 
Vicente Rodolfo Walde Jáuregui - El capital social en las diversas formas de la sociedad anónima, los principios y las diversas funciones que cumple tanto externa como internamente en estas

con capital nuevo, se requiere un acuerdo de modificación de estatutos y un informe técnico que asegure que los créditos quedan suficientemente cubiertos por el capital ya existente. El acuerdo debe expresar el resultado del informe y la manera en que debe efectuarse la reducción de capital. El beneficio contable que derive de una reducción de capital deberá ser afectado exclusivamente a las amortizaciones.

La ley alemana estatuye que la reducción del capital social solo puede ser acordada con el voto favorable de una mayoría de las tres cuartas partes cuando menos del capital presente de la Junta. Los estatutos pueden exigir otra mayoría o imponer otros requisitos. Si existieran varias categorías de acciones el acuerdo de la junta general solo podrá ser válido con el consentimiento separado de cada clase de acciones. Los accionistas que pertenezcan a cada serie tendrán que tomar un acuerdo específico. El acuerdo expresara el día de la reducción y la parte del capital social que debe ser reembolsada. El capital social podrá ser reducido porque hay una reducción del valor nominal de las acciones, porque hay una agrupación de las acciones y en este caso debe respetarse el valor mínimo de la acción. El acuerdo que se adopte debe expresar la manera en que se aplicará la reducción.

De lo que hemos mencionado se puede concluir válidamente que el tema de la reducción y amortización de acciones en su caso es de un carácter técnico y jurídico especial, por ello las sociedades que decidan ejercitar este derecho, que en la Ley Peruana 26887 es una prerrogativa de la Junta General de Accionistas, deberán estudiar prudentemente el ejercicio de esta prerrogativa societaria.

Es del caso mencionar que podemos concluir que durante la vigencia de la S.A. se pueden presentar una serie de alternativas que han de influir decisivamente en la gestión social y que la ley nos propondrá normas que deben ser observadas bajo sanción de nulidad si no se ajustan a los rigores normativos que la norma legal dispone; pero no debemos olvidar, como lo indica la doctrina del Derecho de Sociedades, que el estatuto social se convierte en la propia ley de la empresa mercantil y que las habilidades de los personeros de gestión de los órganos de gobierno de la sociedad pueden conjugar las exigencias legales con la realidad empresarial en las que se apliquen y sin desnaturalizarlas las calidades profesionales y morales del que ejercite la gestión para hacerla exitosa con la decisión que adopte para el mejor logro de las actividades negociales. 